\title{
Local elongation of stretched filled rubber surface
}

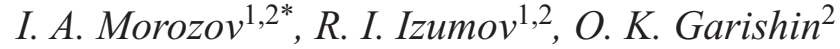 \\ ${ }^{1}$ Institute of continuous media mechanics UB RAS, Academika Koroleva st. 1, 614013 Perm, Russia \\ ${ }^{2}$ Perm State University, Bukireva st. 15, 614990 Perm, Russia
}

Received 3 October 2017; accepted in revised form 8 December 2017

\begin{abstract}
Local elongation of the surface of a stretched rubber is estimated by comparing the stiffness of stretched filled ( 30 or $50 \mathrm{phr}$ of silicica) styrene-butadiene vulcanizate and the results of finite element simulation of the indentation of the unfilled elastomer. The local strain exceeds the macroscopic value, yet the weakly loaded areas are also present. As the macroscopic elongation increases, the oriented polymer strands are formed, whose strain is particularly high. An increase in the filler content significantly increases the number and local elongation of strands. The highest tensile loads of the filled matrix occur in the gaps with the initial size of $100 \mathrm{~nm}$. The limitations of the dynamic indentation of stretched elastomers are shown.
\end{abstract}

Keywords: rubber, mechanical properties, modeling and simulation, atomic force microscopy, local elongation

\section{Introduction}

The filler forms a heterogeneous network of primary units (particles or aggregates), secondary fractal clusters and parts of unbroken granules in the rubber matrix. Due to external loading, the local stress-strain state of a polymer becomes substantially non-uniform. The study structural-mechanical properties of stretched filled elastomers at the scale of filler inclusions is particularly interesting from the point of view of explaining the macroscopic properties of rubber and elaborating sophisticate material models. During the stretching of filled elastomer, the filler is oriented along the axis of deformation, the number of contacts between inclusions increases [1,2], and the electrical resistance of the material falls [3]. The surface of active filler in rubber matrix is covered by glassy-like layer of immobilized polymer chains [4, 5]. According to theory [6-8], this layer gradually goes into matrix (the overall thickness of the modified polymer is $\sim 10 \mathrm{~nm}$ ). Some authors suppose, that being deformed, polymer in this layer is stretched and forms oriented strands $[6,7]$. However, studies of the stretched filled rubber surface show that adjacent inclusions in the stretched material don't go apart, but move in groups and retain their relative position $[9,10]$.

Based on the atomic force microscopy (AFM) measurements, Lame [11] established that the local strains in filled rubber (15 phr of carbon black) are 1.5 times larger than the macroscopic ones in two times stretched material, and the highest inhomogeneities of the strain field appear on the scale up to $1 \mu \mathrm{m}$. Göritz [12] revealed polymer strands in the stretched filled natural rubber (NR) using transmission electron microscopy. The origin of such strands is strain induced orientation and crystallization of NR. Similar pattern was observed in the stretched thin filled rubber film covered with a mesh of cavities [13]. The rubber experiences critical loads in the tip of open cracks. A great number of studies have been carried out to investigate defects and propagation of cracks in various materials under different loading conditions [14], detachment of a polymer matrix in the vicinity of nanoparticles [15] and filler agglomerates 
[16], strain-induced crystallization of natural rubber $[17,18]$ at the crack tip [19], and formation of vacuoles in stretched samples [20,21]. The oriented polymer strands that connect the edges of the open static cracks were studied in the filled and unfilled NR [10].

The information about the local elongation of elastomer matrix in stretched filled rubber, including extreme conditions, like static open cracks, would be very helpful in better understanding the macroscopic behavior of the materials. In this paper, a new approach to estimate local elongation of the matrix surface of filled rubber is proposed. The method is based on a combination of the experimental data (map of stiffness) and the results of finite element modeling of indentation of a stretched elastomer.

\section{Materials and methods}

\subsection{Preparation of samples}

Two styrene-butadiene vulcanizates were prepared by Sumitomo Rubber Industries LTD (Japan) as follows. Nipol SBR 1503 (by ZEON Co.) and the silica Seosil 115 Gr (by Solvay) were used as the main components. The fraction of filler was $30 \mathrm{or} 50 \mathrm{phr}$ (weight parts per 100 parts of rubber). The materials were named as SBR30 and SBR50 respectively. Silane Si 266 (2.4 or $4 \mathrm{phr}$ ) was used to activate the filler surface. The rest of the components (in phr) were: stearic acid $-2, \mathrm{ZnO}-3$, sulphur - 1.58 , antiaging -0.5 , accelerator $N$-Tertiarybutyl-2-benzothiazole sulfennamide (NS) - 1 and accelerator diphenyl guanidine (DPG) -1 . The components were mixed on a two-roll mill. The obtained green rubber was vulcanized in a press mold at $170^{\circ} \mathrm{C}$ and rubber sheets of $2 \mathrm{~mm}$ thickness were made. The vulcanization time was 12 minutes.

The fresh surface of the samples for the AFM measurements was prepared by cutting the pre-stretched sheets with a sharp blade (compression of the cut reduces sample-blade contact). The obtained rubber strips (length $-20 \mathrm{~mm}$, thickness $-2 \mathrm{~mm}$, width of the clean surface $-2 \mathrm{~mm}$ ) were fixed and stretched in a small stretching device and placed under the AFM scanner. The elongation ratio $\lambda=l / l_{0}$ (where $l$ and $l_{0}$ is the actual and initial length) of the material was controlled by measuring the distance between the surface inhomogeneities, visible in optical camera, and was 1.5, 2.5, 3.0, and 3.5.

The surface at the crack tip (open transverse notch) of the stretched sample was examined [10]: small notch ( $\sim 0.5 \mathrm{~mm}$ depth) was made on the edge of the sample. After the stretching, the open notch propagates deeper into the sample and stops. Rubber in this area is in critical stress-strain state: any increase of stretching of the sample may lead to further propagation of the crack. In the AFM experiments, the AFM probe was lowered directly into the open notch and the surface of the crack tip was studied.

Unfilled SBR was not investigated due to the long relaxation time of the stretched surface, which is accompanied by rapid aging. The sticky fractions of the composite appeared on the fresh surface of the sample, dried up and formed a hard layer. Similar phenomena were observed, but not explained, in the work of Dohi et al. [22].

\subsection{AFM experiments}

The experiments were performed on the AFM Dimension Icon in a nanomechanical mapping regime (PeakForce Capture). In this mode, an indentation of the surface with a frequency of $2 \mathrm{kHz}$ occurs simultaneously with relief capturing. Therefore, each point of the surface has its own force curve $F(z)=k d$, where $z$ is the displacement of the probe; $k$ and $d$ are the spring constant and the deflection of the cantilever, respectively.

The scan area was $1.5 \times 1.5 \mu \mathrm{m}$ with $256 \times 256$ points in the $x y$ plane (each point has its own force curve). For the sake of statistics, several images were captured for the each $\lambda$ from the different areas of the sample.

Probes (ScanAsyst-Air) with calibrated $k \sim 0.45 \mathrm{~N} / \mathrm{m}$ and the estimated tip radius $R$ of $\sim 5 \mathrm{~nm}$ were used. The shape of the probe tip was obtained by the blind estimation method [23] using the grating of porous aluminum (PA01 by Mikromash). The value of $R$ was set to the curvature radius of the paraboloid of revolution, which approximates the probe surface in the vicinity of the tip.

An example of the obtained force curve $F(z)$ of SBR is given in Figure 1a. The loading (approaching of the probe to the surface) and unloading parts of the curve are shown. Assuming that the indentation starts at point $(0 ; 0)$, the indentation depth $u$ is: $u=$ $\left(z-z_{0}\right)-\left(d-d_{0}\right)$. The adhesion force $F_{\text {adh }}$, between tip and surface is shown in Figure 1a as well.

The AFM results will be compared with the finite element methods (FEM) simulation data. To this end, the stiffness $S$ was calculated using the loading curve at a given $u=u^{*}$ shown in Equation (1): 

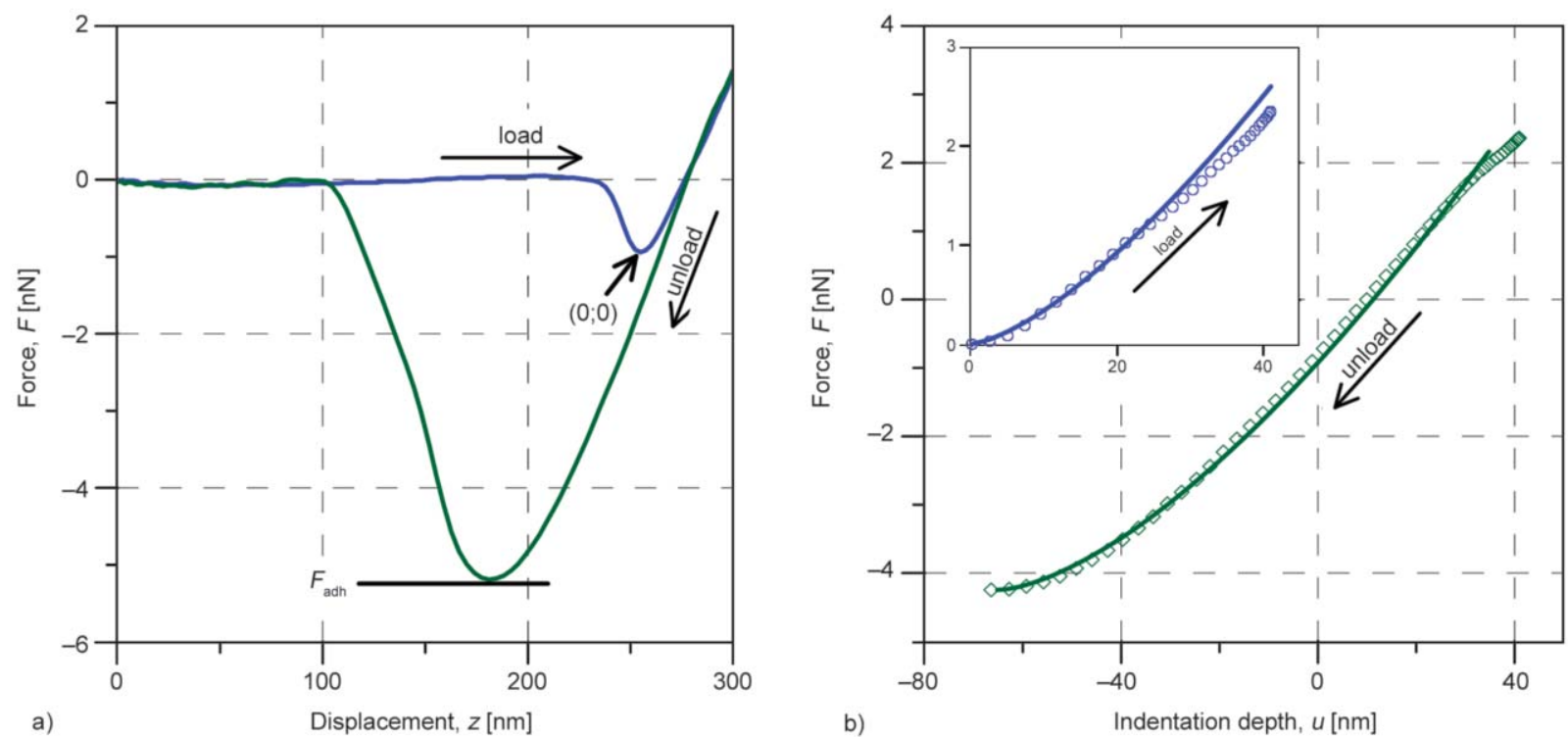

Figure 1. Indentation of the SBR surface: a) full force curve; b) loading and unloading parts of the $F(u)$ : markers - experiment and solid line - approximation (loading $-F=\alpha u^{\mathrm{m}}$, which is close to the Sneddon's model, unloading - JKR model)

$S=\left.\frac{\partial F}{\partial u}\right|_{u=u^{*}}$

The loading part of the experimental curve was approximated by the $F=\alpha u^{\mathrm{m}}$ for $u \leq 5 R$ and then the stiffness was calculated.

The value of stiffness is measured directly in the experiment. Thus, it is the preferred parameter for analysis in the framework of this work. Usually, the indentation curve is used to estimate the elastic modulus $E$. However, its calculation is limited by the assumptions a certain model which are hard to satisfy when indenting the stretched material. Nevertheless, the modulus is of particular interest and was estimated in two ways: by the approximation of loading curve with Sneddon's equation for the paraboloid indenter, see Equation (2) [24]:

$F=\frac{4}{3} \frac{E}{1-v^{2}} u^{1.5} \sqrt{2 R}$

where $v$ is Poisson's ratio $(v=0.5)$; and by the unloading curve and Johnson-Kendall-Roberts (JKR) model [25]. The contact radius $a$ in the JKR model is defined by Equation (3):

$a=\left(\frac{3 R\left(1-v^{2}\right)}{4 E}(\sqrt{1.5 \pi \gamma R}+\sqrt{F+1.5 \pi \gamma R})^{2}\right)^{1 / 3}$

and the indentation depth is given by Equation (4):

$u=\frac{a^{2}}{R}-\sqrt{\frac{6 a \pi \gamma\left(1-v^{2}\right)}{8 E}}$ where $\gamma$ is interfacial energy is defined by Equation (5):

$\gamma=\frac{2 F_{\mathrm{adh}}}{3 \pi R}$

Both approaches are the mechanical models of the Herzian elastic contact of two bodies: hard indenter and soft substrate. In the Sneddon (or Herz) model adhesion interactions are not taken into account; the JKR model considers adhesion inside the contact area. The JKR model was approximated by the equations of Piétrement and Troyon [25] for the fast evaluation of elastic modulus.

The experimental $F(u)$ curve and the approximation results are shown in Figure 1b. The accuracy of the approximation decreases if $u>4 R$ (the calculated $E$ was 1.29 and $2.3 \mathrm{MPa}$ according to Sneddon and JKR models, respectively).

\subsection{Model of indentation of the stretched elastomer}

A contact boundary problem of the indentation of the elastic stretched elastomer (unstretched sample is the cube of side $3 \mu \mathrm{m}$ ) by the hard paraboloid (the curvature radius at apex is equal to the AFM probe tip) has been solved by FEM simulation (ANSYS software, element type is SOLID285).

The mechanical properties of the polymer were simulated by the Ogden elastic potential of the second order. The strain energy density for the uniaxial deformation of incompressible material is given by Equation (6): 
$W=\sum_{i=1}^{2} \frac{\mu_{i}}{\alpha_{i}}\left(\lambda^{\alpha_{i}}+2 \lambda^{-0.5 \alpha_{i}}-3\right)$

where $\mu_{\mathrm{i}}, \alpha_{\mathrm{i}}$ are the constants; $\lambda$ is the elongation ratio. The constants were obtained from the approximation of the uniaxial stress-strain curve of the unfilled SBR (tested in Zwick machine; the strain rate was $25 \% / \mathrm{min}$ ): $\mu_{1}=2.68 \mathrm{~Pa}, \alpha_{1}=7.75, \mu_{2}=$ $-361527 \mathrm{~Pa}, \alpha_{2}=-4.17$. The initial elastic modulus was $2.26 \mathrm{MPa}$.

Initially, the probe touches the upper edge of the cube. Then, two opposite sides of the cube move apart to achieve the prescribed elongation ratio of the material: $\lambda=1,2,3,4,5,6,7$. The 'sample' is then fixed and indented by stepwise displacement of the probe. Preliminary calculations has shown, that friction coefficient has no sufficient effect on the results of modelling, therefore it was set to zero. An illustration of six times stretched model is given in Figure 2.

Based on the FEM results, the indentation force $F$ versus depth $u$ was obtained for the considered $\lambda$.

Stretching the material changes the cross-section of indentation contact area. In the case of stretched polymer it has an elliptical shape. The size in the direction orthogonal to the tension is $R_{\mathrm{z}}$ the radius of the hyperboloid cross-section, and in the direction of elongation is $R_{6}>R_{\mathrm{Z}}$ (see insert in Figure 2). The calculation of area of such deformed cross-section is complicated. Moreover, surface energy of the rubber increases upon applying a deformation [26], this affects $F_{\text {adh }}$. Thus, the accurate implementation of the existing theories (Herz, JKR) for determining the 'elastic modulus' (this is not the traditional mechanical constant of the material) of the stretched material is unclear.

Therefore, for the comparison with the experiment, the stiffness defined by Equation (1) was calculated using FEM $F(u)$ curves. For the completeness of the study, the elastic modulus was evaluated from the simulation curves by the Sneddon's equation.

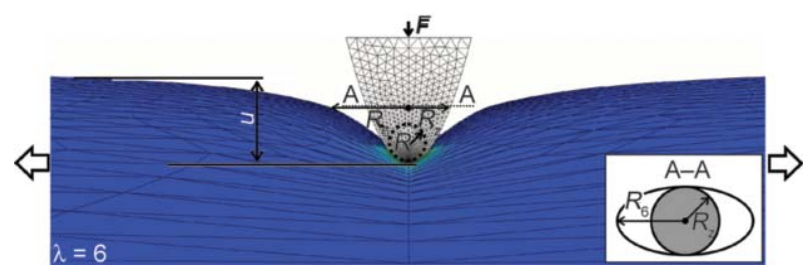

Figure 2. FEM model of indentation of six times stretched material. The cross-section of indentation imprint is given in the insert.

\section{Results and discussion}

The results of FEM simulation are shown in Figure 3. The indentation force $F(u)$ grows with strain (see insert in Figure 3). The relative (to the stiffness $S_{0}$ of the unstretched material) stiffness of the stretched elastomer was calculated for the indentation depth $u^{*}=5,10$, and $15 \mathrm{~nm}$ and given in Figure 3. It rises rapidly and at $\lambda=7$ exceeds by two orders the undeformed material.

The change of $u^{*}$ from 5 to $15 \mathrm{~nm}$ does not affect the relative stiffness for the fixed $\lambda$. Thus, in further discussion, $u^{*}=10 \mathrm{~nm}$ is used. The values of stiffness for $\lambda>7$ will be necessary, therefore the curve in Figure 3 was extrapolated by the power function.

The AFM images of the unstretched SBR30 are given in Figure 4. Filler inclusions and agglomerates are marked by contours. The filler has low adhesion and indentation depth and looks dark in the corresponding maps; a bright area is the polymer matrix. Definition of filler boundaries is the important part of this study. The surface regions that affected by the filler should be excluded from the consideration. For this case, the frequency distributions of adhesion and indentation depth were plotted (see inserts in Figure 4). The pronounced maximum corresponds to the matrix. The surface regions with lower values are somehow affected by the filler (filler and polymerfiller transitions or filler covered by some polymer layer) and excluded from further study. For this case,

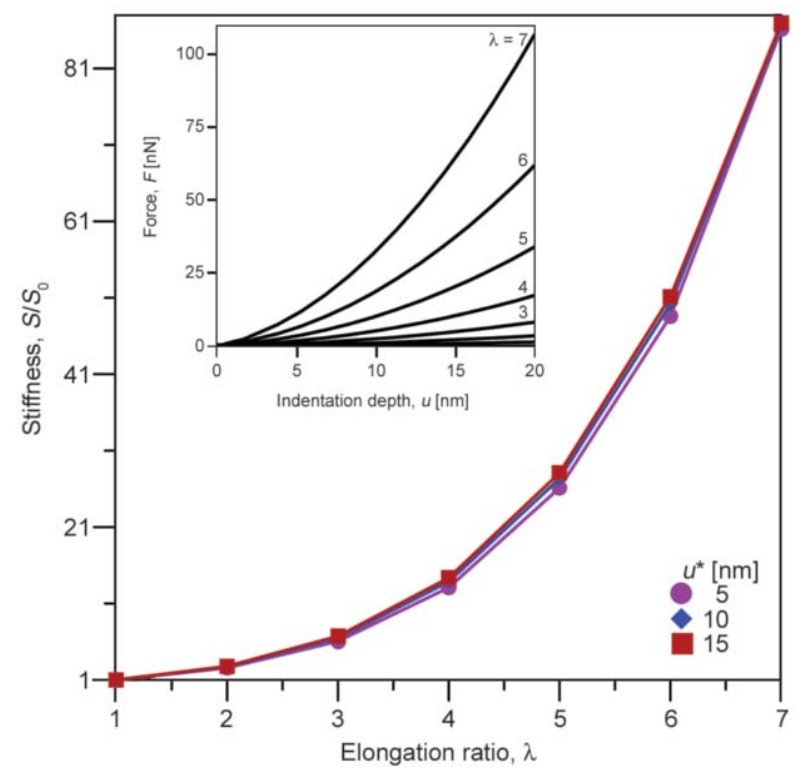

Figure 3. FEM results: applied force $F$ versus indentation depth $u$ and relative stiffness of the stretched elastomer 

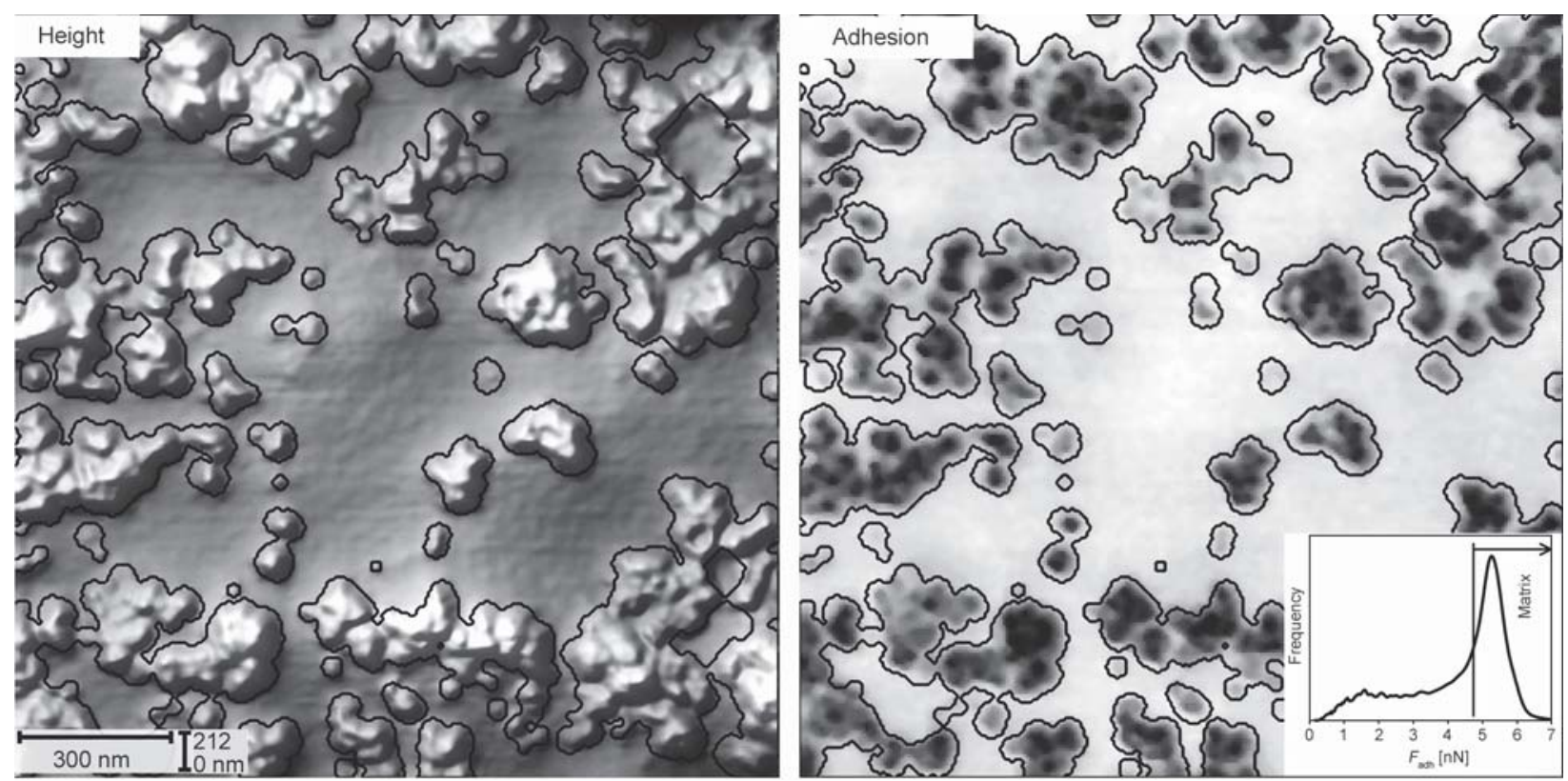

a)

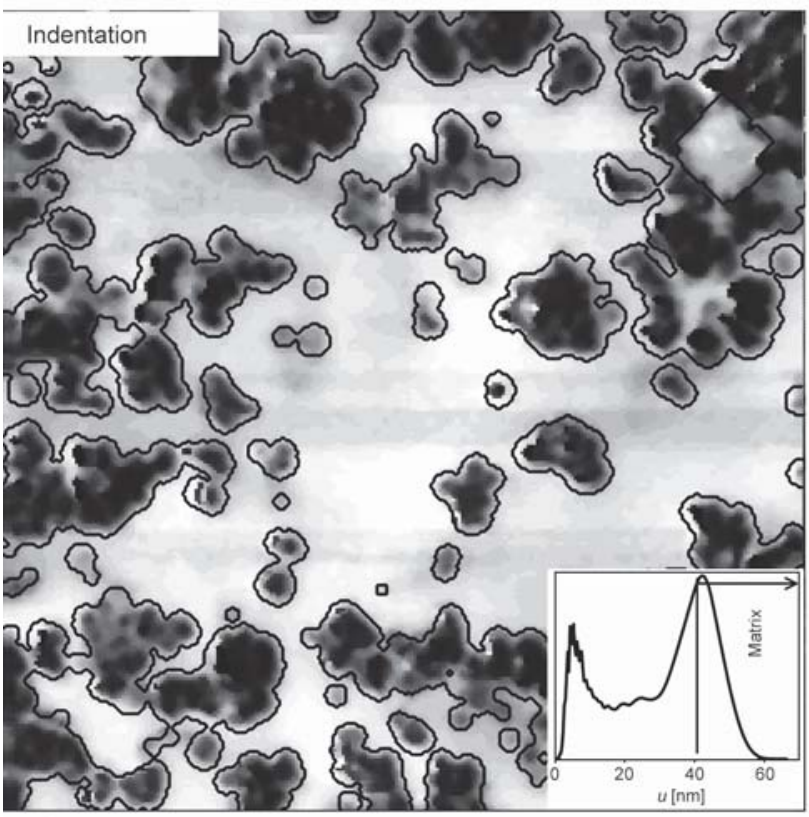

c)

b)

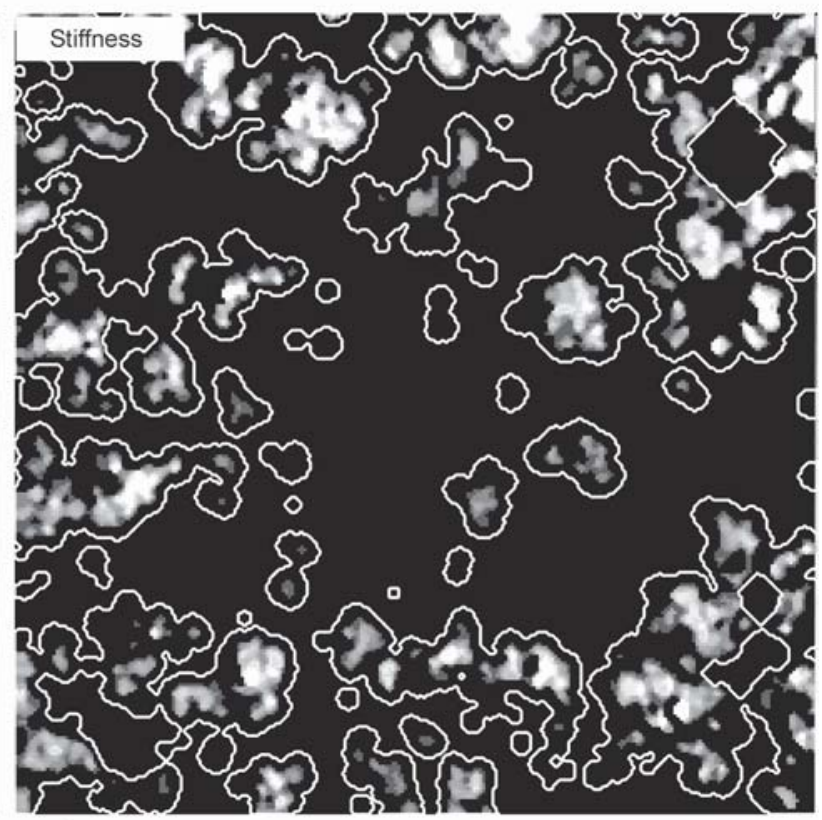

Figure 4. AFM-images $1.5 \times 1.5 \mu \mathrm{m}$ of unstretched SBR30: maps of height, tip-sample adhesion, indentation depth and stiffness at $u^{*}=10 \mathrm{~nm}$. Filler boundaries are shown by contours maps of height (a), tip-sample adhesion (b), indentation depth (c) and stiffness (d)

both maps were used: adhesion better accounts the rough surface of open inclusions, indentation depth - filler covered by polymer.

Thus, the regions of filler were roughly marked. The values of adhesion and indentation depth of highly stretched matrix are low and could lead to incorrect definition of filler. Therefore, the marked filler contours were inspected and corrected in custom editor, if needed.

Finally, the filler contours were expanded by the dilation (operation of mathematical morphology) with a circular structural element of $5 \mathrm{~nm}$. By this way, polymer-filler transitions (these places has steep slopes which lead to inaccurate indentation curves) were included into the filler contours, and the narrow gaps between filler boundaries were closed (in such places the contact of AFM probe with the sample is undefined). Note, that this procedure excludes immobilized polymer layer from the observation and the true filler boundaries are overestimated.

In further discussion, only the surface of a polymer matrix is studied. The stiffness distribution of the 
undeformed matrix (see the map in Figure 4) has a Gaussian-like shape (not shown here); the experimental value of $S_{0}$ is the maximum of this distribution.

A correspondence between the AFM data and the FEM simulation results should be verified. The experimental $S_{0}=0.034 \mathrm{nN} / \mathrm{nm}$ is lower than the simulation result $-0.065 \mathrm{nN} / \mathrm{nm}$. This discrepancy is due to the dynamic characteristics of the experiment (high indentation rate), the viscoelastic properties of the material, and the adhesion and capillary forces at the probe-surface interface.

Figure 5 shows the averaged experimental curve $F(u)$ of the indentation of the unstretched matrix. The multiplication of these values by the factor $\kappa=$ 1.4 gives a good fit with the simulation for the $u \leq$ $15 \mathrm{~nm}$.

It is assumed that $\kappa$ is affected by the stretching of the material insignificantly. Therefore, the impact of all indefinite factors is represented by one fitting parameter $\kappa$, which disappears in the case of relative stiffness. (Analysis of all the results showed that $\kappa$ slightly increases: $\kappa=1.4$ if the elongation is $1 \ldots 3$; 1.5 for $4 \ldots 6 ; 1.6$ for $\geq 7$.)

Thus, the local elongation ratio $\lambda_{\text {loc }}$ of the matrix could be measured by the comparison of the relative stiffness from the AFM-experiment (Figure 4) with the FEM-model (Figure 3).

Surface and map of local elongation of the stretched 1.5, 3 and 3.5 times SBR30 and SBR50 are shown in Figures 6-8. The strain direction is vertical.

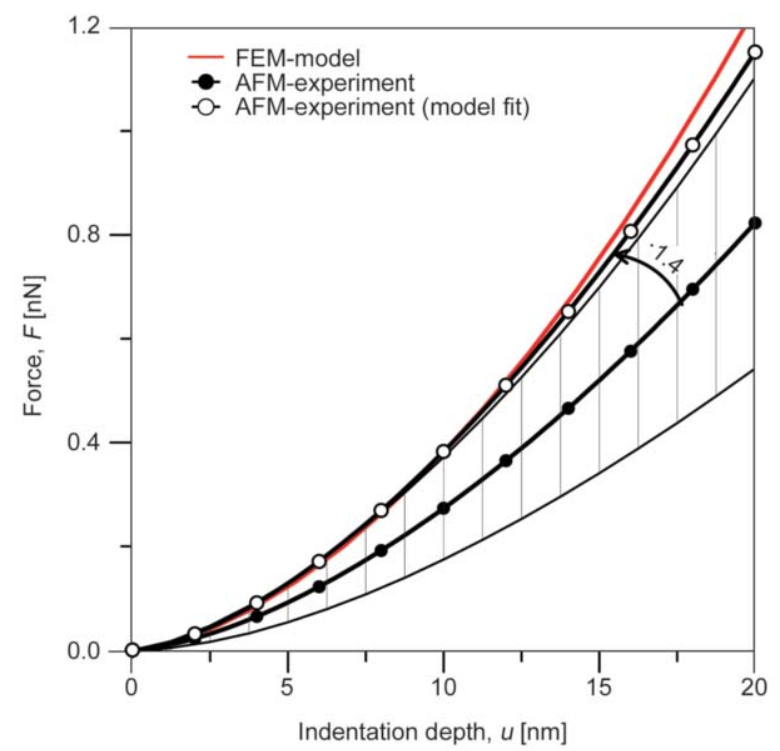

Figure 5. Indentation of the unstretched matrix: the experimental force curve (mean value and deviation are shown) and the FEM-simulation
Large filler agglomerates are visible at low tension (Figure 6), as $\lambda$ increases they break into smaller parts (Figures 7 and 8).

Polymer strands (width $20 \ldots 100 \mathrm{~nm}$ ) - are visible on the stretched surface. The origin of such strands is local orientation of the polymer due to high extension of the matrix in the gap between filler particles. The number of these strands and $\lambda_{\text {loc }}$ increase both with growing the filler fraction and with macroscopic elongation of the material. The strands start to appear at $\lambda \approx 2$ in the SBR30. A considerable amount of strands were observed in SBR50 even at $\lambda=1.5$ (Figure 6b).

The fraction of the overloaded matrix, where $\lambda_{\mathrm{loc}}>\lambda$, in the SBR30 increases almost twice (see Figure 9a) as the macroscopic strain grows; at $\lambda=3.5$ half of the matrix of SBR30 experiences high loads. In SBR $50,75 \%$ of the matrix is overloaded already at low $\lambda$; with a further macroscopic extension, this value increases slightly.

The regions where $\lambda_{\text {loc }}<\lambda$ also present on the rubber surface. In one case, the polymer is substantially shielded by the filler from external load (Figure 6a), so-called occluded polymer. In another case, the material adjacent to the strands also has lower tension: the strands bear the main strain and unload the surrounding matrix.

The distributions of $\lambda_{\text {loc }}$ (Figure 9b, 9c) in the SBR30 shift to the right with increase of $\lambda$. As for the SBR50, the changes in the peak values are not so significant, but the $\lambda_{\text {loc }}$ is expanded to higher values. This means, that in the highly filled SBR50 the filler confines the growth of new areas of the oriented matrix; further deformation leads to stretching the already highly loaded matrix. In the low-filled SBR30, the local elongations grow (and redistribute to weakly loaded matrix) more uniformly.

Figure 10 shows the average values of $\lambda_{\text {loc }}$ in the gaps in relation to the gap size (distance between filler contours of strained sample). The gap was defined as the path between two filler contours located one below another, if $\lambda_{\text {loc }} \approx$ const on this path. Therefore, only oriented parts of the matrix were taken into account.

In general, up to the threefold stretching of the sample, the elongation in the gaps of SBR30 slightly decreases as the gap grows. At this stage, the material is stretched due to the redistribution of the load over the weakly loaded matrix and the opening of new 

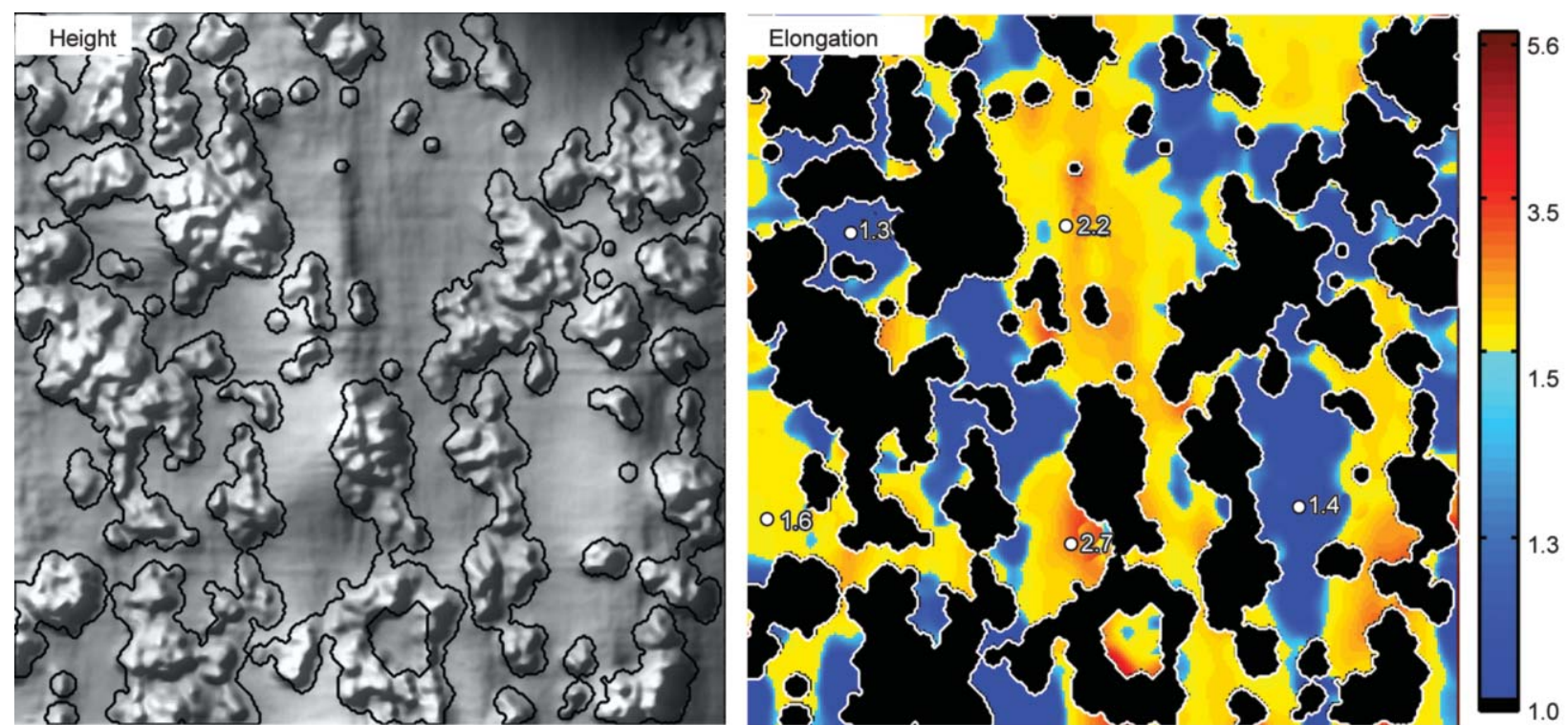

a)
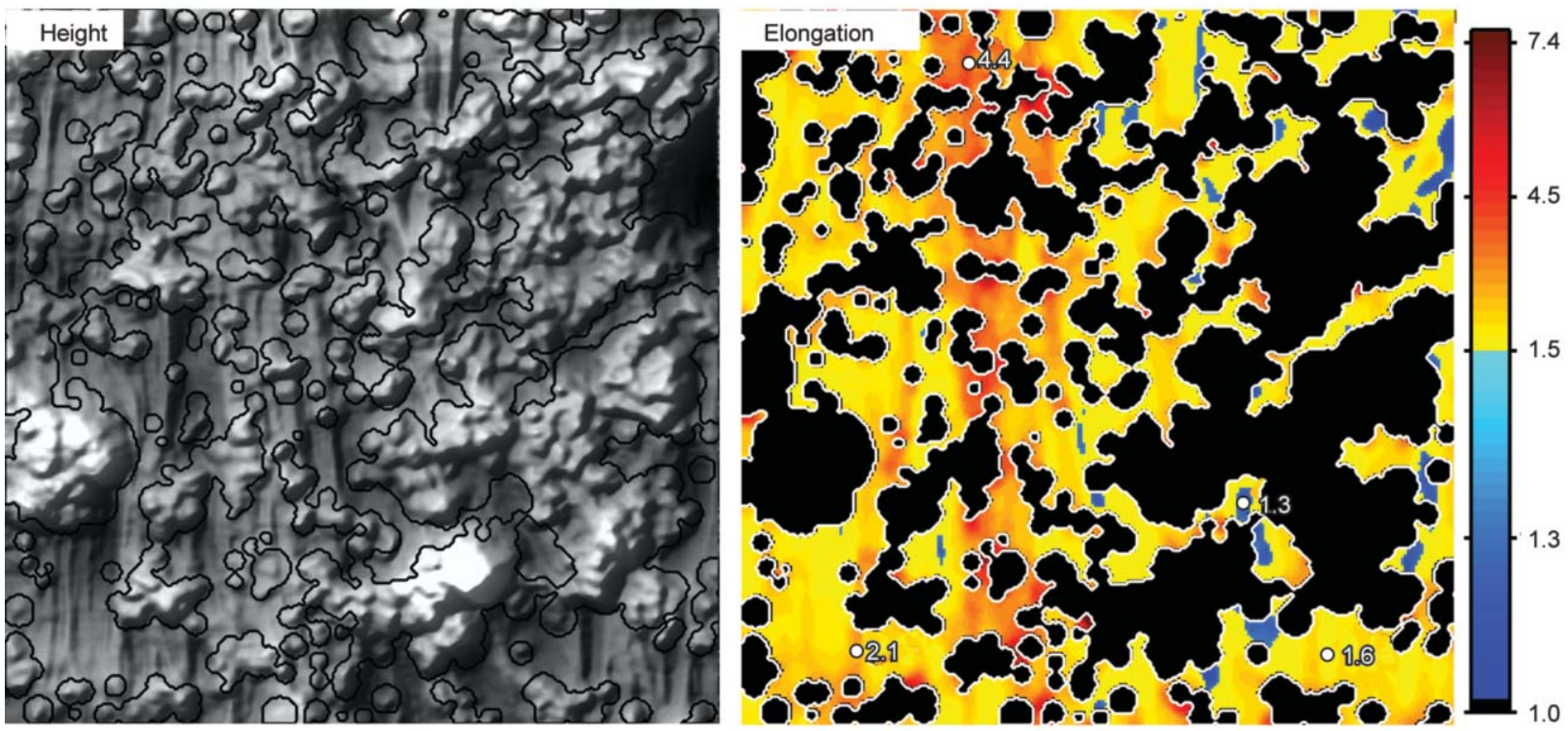

b)

Figure 6. Surface height $(1.5 \times 1.5 \mu \mathrm{m})$ and local elongation ratio of 1.5 times stretched SBR30 (a) and SBR50 (b). The values of $\lambda_{\text {loc }}$ are shown in certain points.

gaps. At $\lambda=3.5$ elongation in the large gaps starts to increase, i.e. the oriented matrix was formed in the material and takes the main load.

In SBR50, at $\lambda>2$ the strain is redistributed over the large areas of the matrix, where the distance between inclusions of the filler is large. The matrix in the small gaps is stretched relatively weakly, i.e. close filler inclusions (parts of the agglomerates) move in groups during deformation.

The maxima of the graphs (Figure 10) are shifted to the right as $\lambda$ increases (especially pronounced for SBR50) and correspond to the length of oriented strands. Knowing these gaps and $\lambda_{\text {loc }}$, the initial distance between the filler fragments was calculated:
$80 \ldots 220 \mathrm{~nm}$ for SBR30 and $100 \ldots 200 \mathrm{~nm}$ for SBR50. This is the initial gap where the polymer matrix bears the maximum load under tension.

In the vicinity of the crack tip (Figure 11), the surface of the filled material is covered with long strands and local ruptures. The elongation of the strands is $2 . . .3$ times higher than the elongation at break of the macroscopic sample. At the same time regions, where $\lambda_{\text {loc }}$ is low, are visible - the microcracks.

In addition, the peculiarities of the mechanical interaction of the AFM probe with a stretched elastomer were studied. The contact area of the probe and the stretched material (see insert in Figure 2) reduces, therefore the probe-sample adhesion (relative to the 

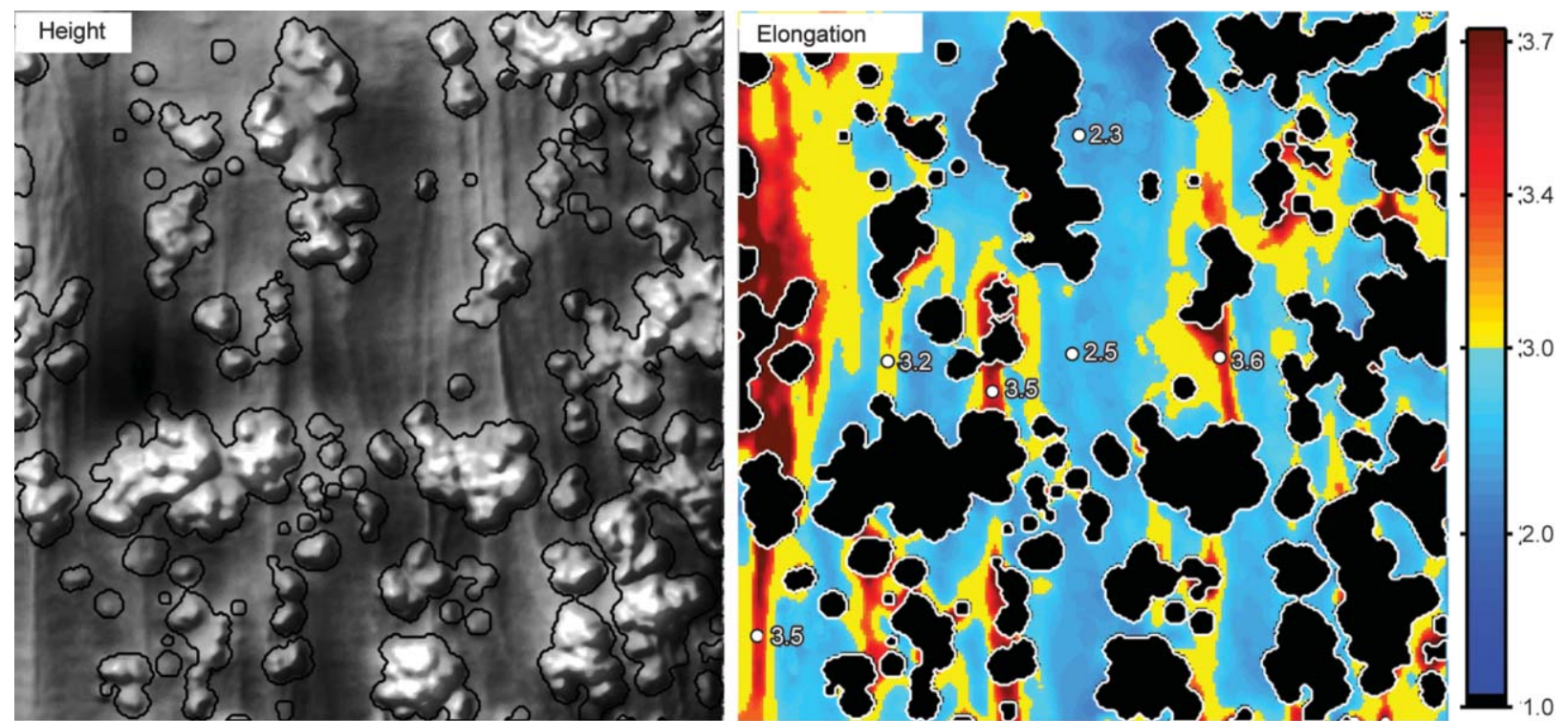

a)
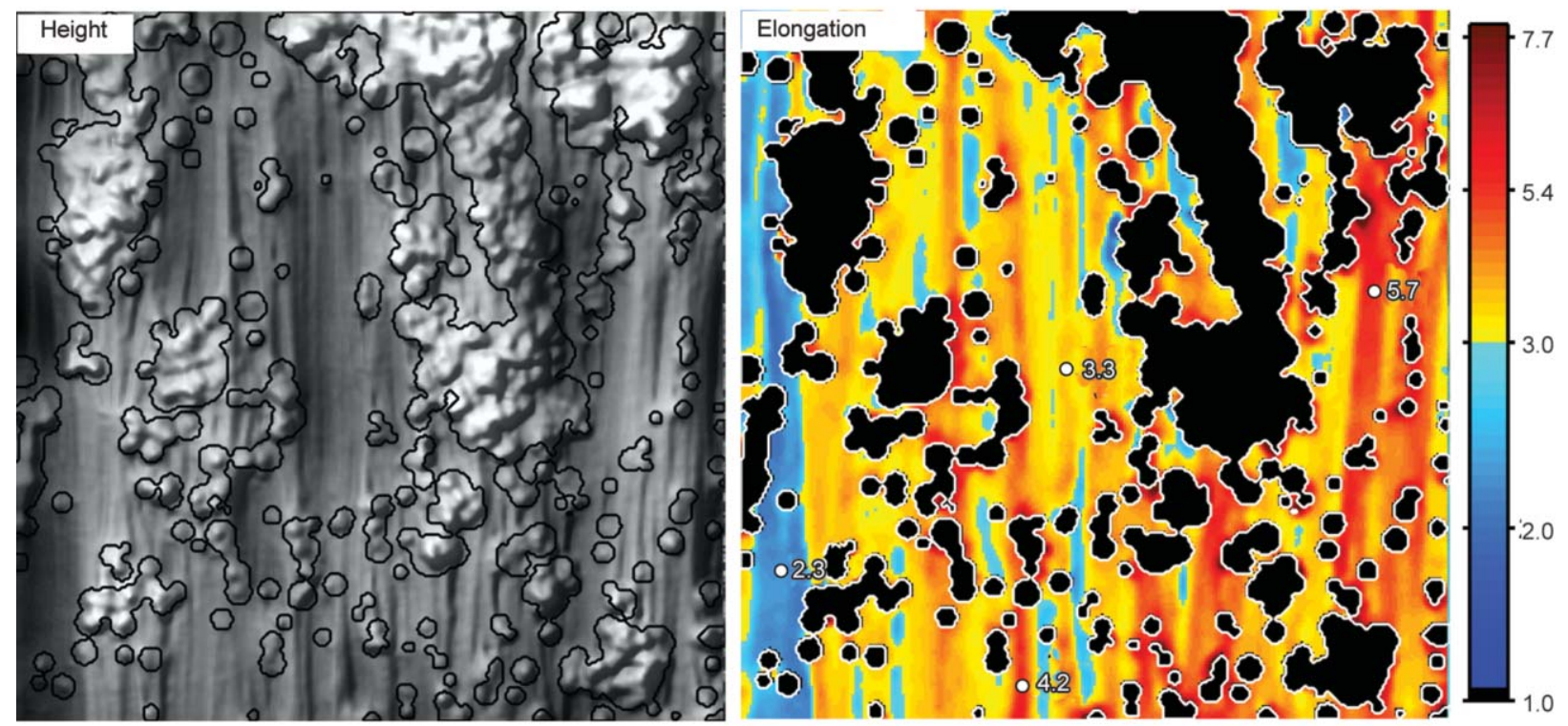

b)

Figure 7. Surface height $(1.5 \times 1.5 \mu \mathrm{m})$ and local elongation ratio of 3 times stretched SBR30 (a) and SBR50 (b). The values of $\lambda_{\text {loc }}$ are shown in certain points.

applied force) sharply falls even at small $\lambda_{\text {loc }}$ and then decreases insignificantly (Figure 12a).

The values of the elastic modulus of the unstretched matrix are as follows: 2.0 MPa (Sneddon's approximation of FEM model), 1.29 MPa (AFM loading curve and Sneddon's model), 2.3 MPa (AFM unloading curve and JKR model). Thus, the calculations based on the loading curve give the underestimated modulus; the JKR-model is close to the macroscopic value (2.26 MPa).

However, the application of the JKR model to the stretched material has shown that at $\lambda_{\text {loc }}>4$ the results are lower than the calculations of the Sneddon's model (Figure 12b). At the same time, the 'elastic moduli' of stretched rubber, calculated by the Sneddon's model using the AFM and FEM data, coincide quite well (Figure 12b), Therefore, the Sneddon's model could be also used to compare the FEM simulation and the experiment.

The results of the JKR-model can be explained by the analysis of the force curves of the nanomechanical mapping regime. In some cases, the unloading curve goes above the load curve, and $F$ increases in the vicinity of the maximum $u$ for some time even at unloading. Apparently, this is due to the rapid restoration of the surface after indentation. The material pushes out the probe faster than the cantilever's base is retracted from the surface and the deflection 

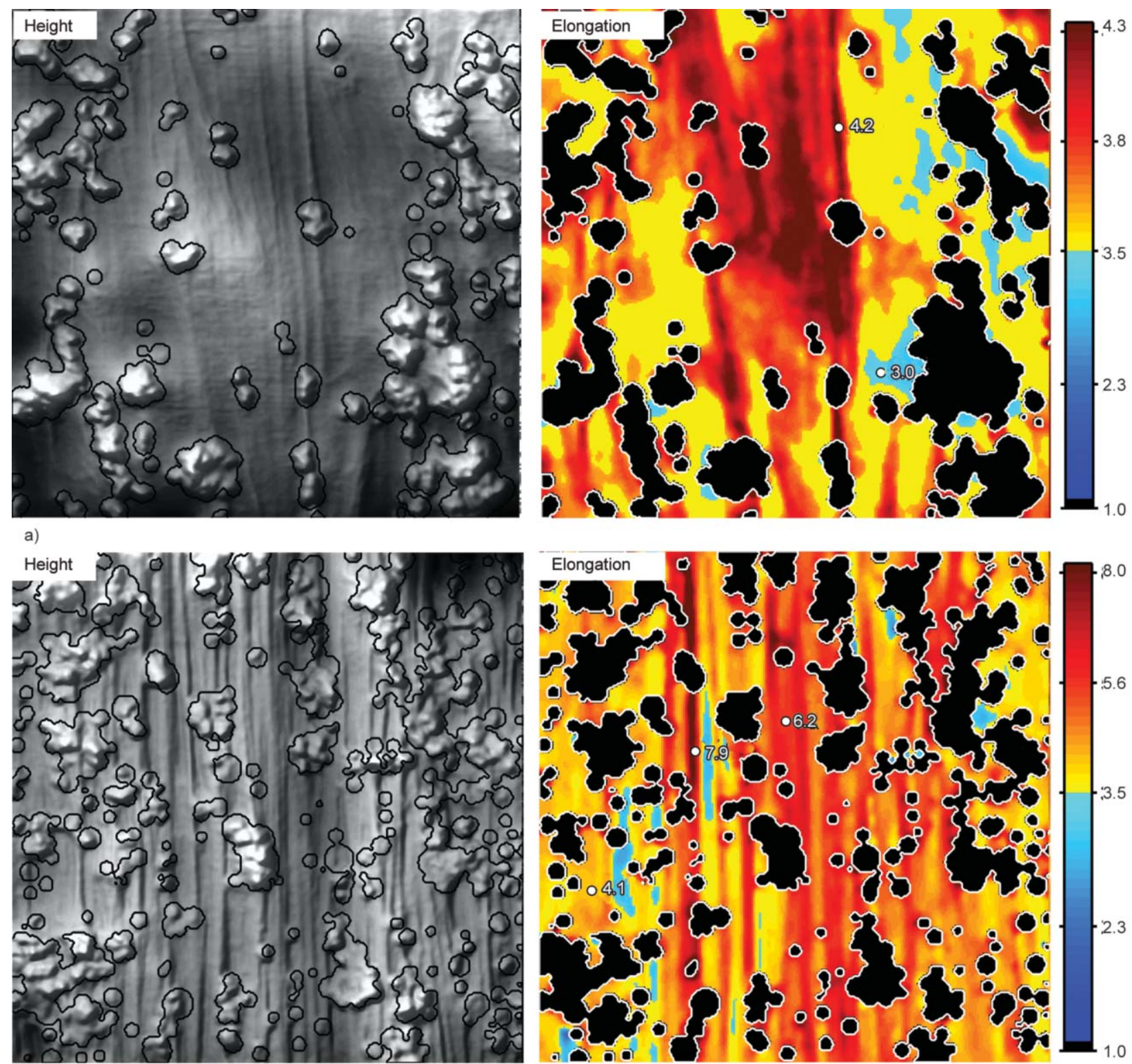

b)

Figure 8. Surface height $(1.5 \times 1.5 \mu \mathrm{m})$ and local elongation ratio of 3.5 times stretched SBR30 (a) and SBR50 (b). The values of $\lambda_{\text {loc }}$ are shown in certain points.

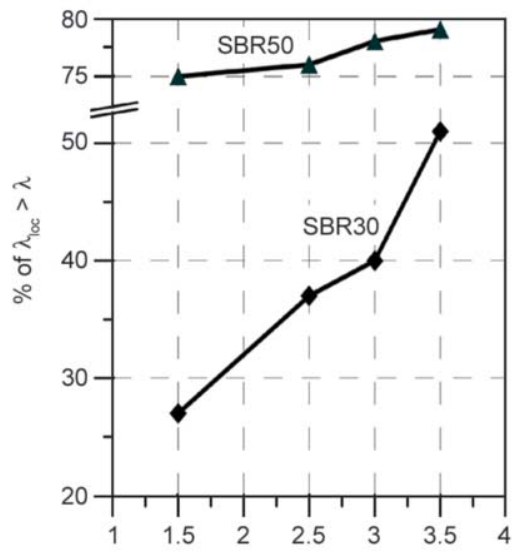

a) Macroscopic elongation ratio, $\lambda$

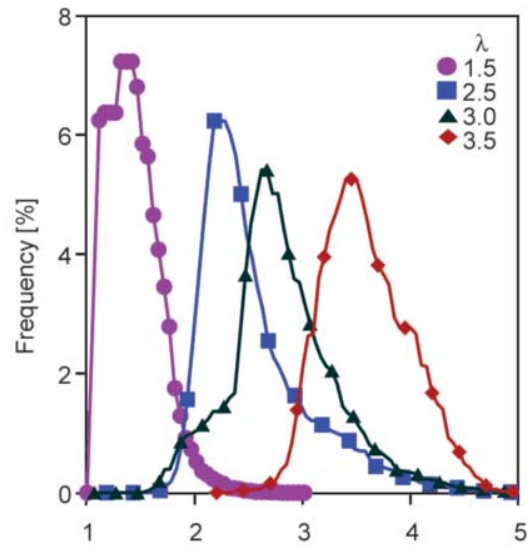

b) Local elongation ratio, $\lambda_{\text {loe }}$

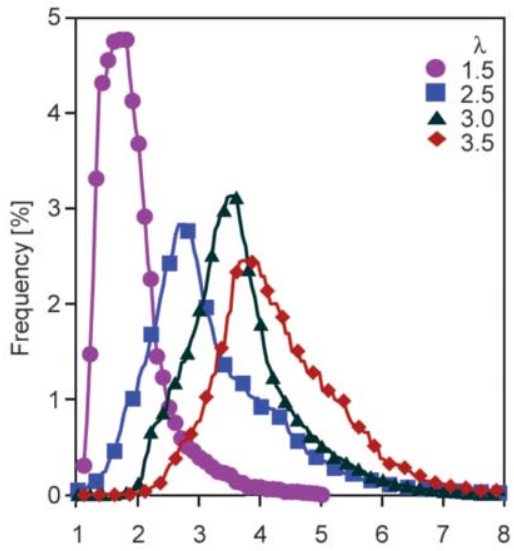

c) Local elongation ratio, $\lambda_{\text {loc }}$

Figure 9. Fraction of overloaded matrix (a) and distributions of $\lambda_{\text {loc }}$ in SBR30 (b) and SBR50 (c) 


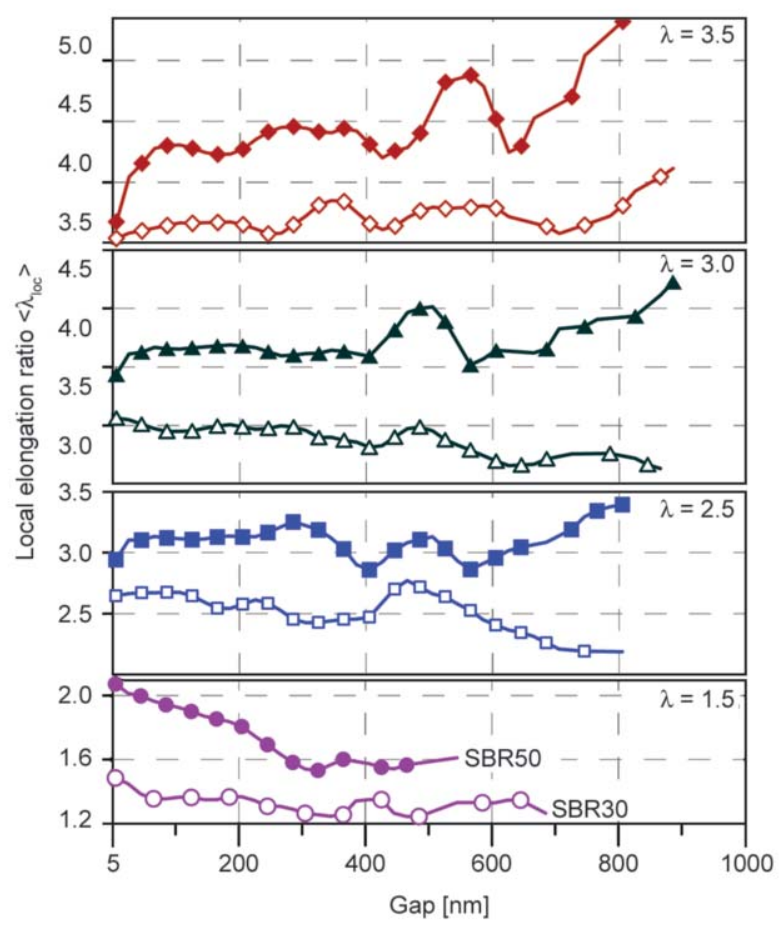

Figure 10. Average elongations in the gaps for SBR30 (open markers) and SBR50 (filled markers)

of the cantilever is reduced. This effect is enhanced by the low adhesion and small indentation depth of the stretched material.

Therefore, a certain combination of experimental parameters (applied load, material properties) and the high indentation rate of PeakForce regime can lead to distortion of unloading force curves and incorrect results.

\section{Conclusions}

The local elongation ratio of the surface of a polymer matrix of a filled butadiene-styrene vulcanizate at the length scale of filler inclusions was determined by atomic force microscopy and finite element modeling. The local elongation is $1.5 \ldots 2$ times greater than the macroscopic elongation and depends on both the filler fraction and the applied load. However, the regions where the local deformation is less than the macroscopic one (occluded polymer) also exist. As a result of stretching, oriented polymer strands are formed on the surface, their elongation is particularly high in comparison with the surrounding polymer.

As the macroscopic tension increases, $\lambda_{\text {loc }}$ in $30 \mathrm{phr}$ filled SBR grows gradually, spreading to the weakly loaded matrix. In the highly filled SBR50, local elongations increase sharply in the entire matrix at the initial stage of loading.

A comparison of the local elongation and the distance between the inclusions has shown that the matrix experiences the highest tensile loads in the gaps with the initial size of $\sim 100 \mathrm{~nm}$. The adjacent inclusions under deformation retain their relative position in the groups of small agglomerates. This contradicts the popular theory $[6,7]$, according to which the most loaded part of the matrix is in the small gaps at the vicinity of polymer-filler interphase. Our experimental studies have shown that the more preferable scenario is the redistribution of the load over the relatively filler-free areas of the matrix than the moving apart of adjacent inclusions.

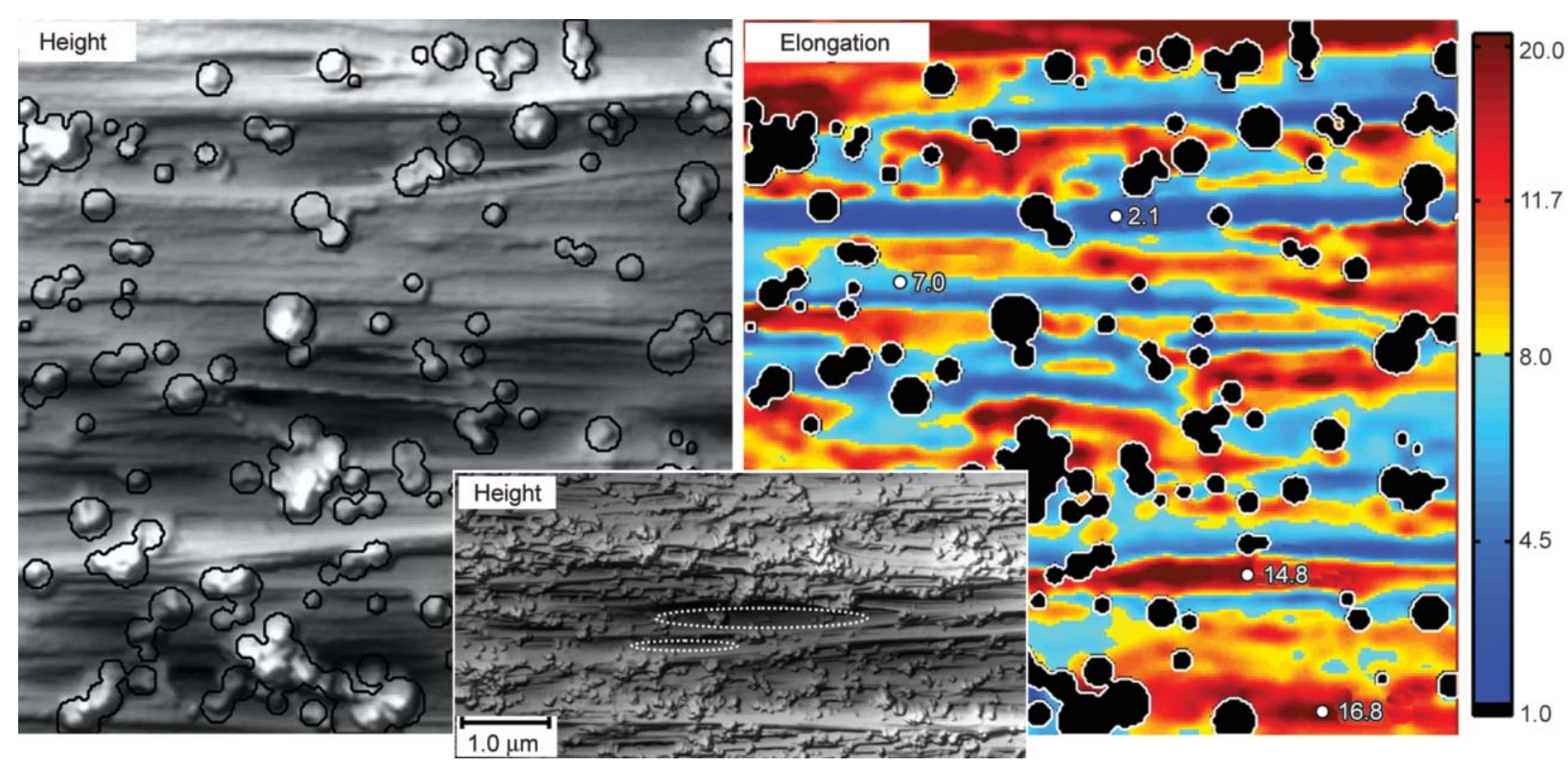

Figure 11. Surface height $(1.5 \times 1.5 \mu \mathrm{m})$ and local elongation ratio at the crack tip of SBR30. The elongation axis is horizontal. The representative AFM image is shown in insert and the local ruptures are marked. 

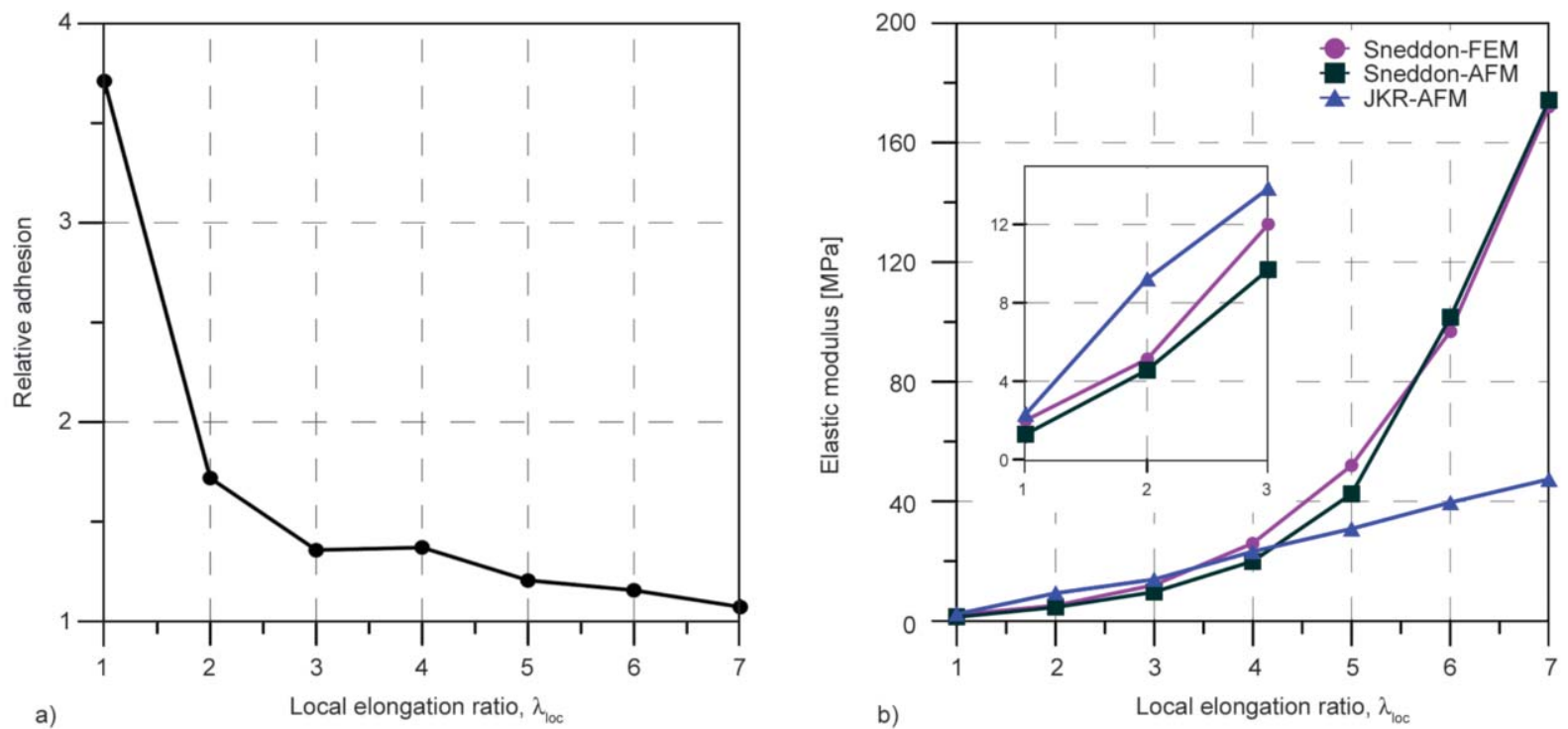

Figure 12. Plot of adhesion (a) and elastic modulus (b) vs. elongation ratio

Long strands and microfractures were revealed on the surface of the crack tip. The elongation of such strands is $2 \ldots 3$ times higher than the macroscopic strain at break. At the same time, deformation in the area of microfractures is relatively small.

The experimental values of the elastic modulus (calculated using the loading part of the indentation force curve) were in good agreement with the FEMsimulation results for any elongation ratio. However, the calculations based on the unloading curve and the JKR-model gave distorted results for the high elongation ratios.

\section{Acknowledgements}

The work was supported by RFBR Grant 15-08-03881.

\section{References}

[1] Maas S., Gronski W.: Deformation of filler morphology in strained carbon black loaded rubbers. A study by atomic force microscopy. Rubber Chemistry and Technology, 68, 652-659 (1995).

https://doi.org/10.5254/1.3538764

[2] Le Diagon Y., Mallarino S., Fretigny C.: Particle structuring under the effect of an uniaxial deformation in soft/hard nanocomposites. The European Physical Journal E, 22, 77-83 (2007).

https://doi.org/10.1140/epje/e2007-00013-2

[3] Yamaguchi K., Busfield J. J. C., Thomas A. G.: Electrical and mechanical behavior of filled elastomers. I. The effect of strain. Journal of Polymer Science Part B: Polymer Physics, 41, 2079-2089 (2003).

https://doi.org/10.1002/polb.10571
[4] Litvinov V. M., Steeman P. A. M.: EPDM-carbon black interactions and the reinforcement mechanisms, as studied by low-resolution ${ }^{1} \mathrm{H}$ NMR. Macromolecules, 32, 8476-8490 (1999). https://doi.org/10.1021/ma9910080

[5] Berriot J., Montes H., Lequeux F., Long D., Sotta P.: Gradient of glass transition temperature in filled elastomers. Europhysics Letters, 64, 50-56 (2003). https://doi.org/10.1209/epl/i2003-00124-7

[6] Fukahori Y.: New progress in the theory and model of carbon black reinforcement of elastomers. Journal of Applied Polymer Science, 95, 60-67 (2005). https://doi.org/10.1002/app.20802

[7] Stöckelhuber K. W., Svistkov A. S., Pelevin A. G., Heinrich G.: Impact of filler surface modification on large scale mechanics of styrene butadiene/silica rubber composites. Macromolecules, 44, 4366-4381 (2011). https://doi.org/10.1021/ma1026077

[8] Papon A., Montes H., Hanafi M., Lequeux F., Guy L., Saalwächter K.: Glass-transition temperature gradient in nanocomposites: Evidence from nuclear magnetic resonance and differential scanning calorimetry. Physical Review Letters, 108, 065702/1-065702/5 (2012). https://doi.org/10.1103/PhysRevLett.108.065702

[9] Morozov I. A., Lauke B., Heinrich G.: Quantitative microstructural investigation of carbon-black-filled rubbers by AFM. Rubber Chemistry and Technology, 85, 244-263 (2012).

https://doi.org/10.5254/rct.12.88990

[10] Morozov I. A.: Structural-mechanical AFM study of surface defects in natural rubber vulcanizates. Macromolecules, 49, 5985-5992 (2016).

https://doi.org/10.1021/acs.macromol.6b01309

[11] Lame O.: Does fractal nanostructure of filled rubber lead to fractal deformations? In situ measurements of strain heterogeneities by AFM. Macromolecules, 43, 5881-5887 (2010). https://doi.org/10.1021/ma100697v 
[12] Göritz D.: Properties of rubber elastic systems at large strains. Die Angewandte Makromolekulare Chemie, 202, 309-329 (1992). https://doi.org/10.1002/apmc.1992.052020118

[13] Dohi H., Kimura H., Kotani M., Kaneko T., Kitaoka T., Nishi T., Jinnai H.: Three-dimensional imaging in polymer science: Its application to block copolymer morphologies and rubber composites. Polymer Journal, 39, 749-758 (2007).

https://doi.org/10.1295/polymj.PJ2006259

[14] Brüning K.: In-situ Structure characterization of elastomers during deformation and fracture. Springer, Dresden (2014).

https://doi.org/10.1007/978-3-319-06907-4

[15] Zhang H., Scholz A. K., de Crevoisier J., Vion-Loisel F., Besnard G., Hexemer A., Brown H. R., Kramer E. J., Creton C.: Nanocavitation in carbon black filled styrene-butadiene rubber under tension detected by real time small angle $\mathrm{X}$-ray scattering. Macromolecules, 45, 1529-1543 (2012). https://doi.org/10.1021/ma2023606

[16] Huneau B., Masquelier I., Marco Y., le Saux V., Noizet S., Schiel C., Charrier P.: Fatigue crack initiation in a carbon black-filled natural rubber. Rubber Chemistry and Technology, 89, 126-141 (2016).

https://doi.org/10.5254/rct.15.84809

[17] Beurrot-Borgarino S., Huneau B., Verron E., Rublon P.: Strain-induced crystallization of carbon black-filled natural rubber during fatigue measured by in situ synchrotron X-ray diffraction. International Journal of Fatigue, 47, 1-7 (2013).

https://doi.org/10.1016/j.ijfatigue.2012.07.001

[18] Toki S., Sics I., Hsiao B. S., Murakami S., Tosaka M., Poompradub S., Kohjiya S., Ikeda Y.: Structural developments in synthetic rubbers during uniaxial deformation by in situ synchrotron X-ray diffraction. Journal of Polymer Science Part B: Polymer Physics, 42, 956-964 (2004).

https://doi.org/10.1002/polb.10679
[19] Brüning K., Schneider K., Roth S. V., Heinrich G.: Strain-induced crystallization around a crack tip in natural rubber under dynamic load. Polymer, 54, 62006205 (2013). https://doi.org/10.1016/j.polymer.2013.08.045

[20] Gent A. N., Lindley P. B.: Internal rupture of bonded rubber cylinders in tension. Proceedings of the Royal Society A: Mathematical, Physical and Engineering Sciences, 249, 195-205 (1959). https://doi.org/10.1098/rspa.1959.0016

[21] Zhang H., Scholz A. K., de Crevoisier J., Berghezan D., Narayanan T., Kramer E. J., Creton C.: Nanocavitation around a crack tip in a soft nanocomposite: A scanning microbeam small angle X-ray scattering study. Journal of Polymer Science Part B: Polymer Physics, 53, 422429 (2015). https://doi.org/10.1002/polb.23651

[22] Dohi H., Sakai M., Tai S., Nakamae H., Kimura H., Kotani M., Kishmoto H., Kobe Y. M.: Atomic force microscopy study on mesh structure formed on stretched rubber surface. Kautschuk Gummi Kunststoffe, 60, 5255 (2007).

[23] Villarrubia J. S.: Algorithms for scanned probe microscope image simulation, surface reconstruction and tip estimation. Journal of Research of the National Institute of Standards and Technology, 102, 425-454 (1997). https://doi.org/10.6028/jres.102.030

[24] Sneddon I. N.: The relation between load and penetration in the axisymmetric boussinesq problem for a punch of arbitrary profile. International Journal of Engineering Science, 1, 47-57 (1965). https://doi.org/10.1016/0020-7225(65)90019-4

[25] Piétrement O., Troyon M.: General equations describing elastic indentation depth and normal contact stiffness versus load. Journal of Colloid and Interface Science, 226, 166-171 (2000). https://doi.org/10.1006/jcis.2000.6808

[26] Maeda K., Bismarck A., Briscoe B.: Effect of bulk deformation on rubber adhesion. Wear, 263, 1016-1022 (2007). https://doi.org/10.1016/j.wear.2007.02.002 